\title{
Rapid pneumatic and Mackay-Marg applanation tonometry to evaluate the postural effect on intraocular pressure
}

\author{
M. R. JAIN AND V. J. MARMION \\ From Bristol Eye Hospital, Bristol
}

Glaucoma is usually considered to be adequately controlled when Goldmann applanation readings are below $22 \mathrm{mmHg}$. It is, however, now known that the intraocular pressure increases to a varying degree when the patient changes his posture from sitting to a recumbent position (Galin, McIvor, and Magruder, 1963; Roberts and Rogers, 1964; Hetland-Eriksen, 1966a; Inglima, 1966; Tarkkanen and Leikola, 1967; Langham and McCarthy, r968; Anderson and Grant, I973). Hetland-Eriksen $(1966 \mathrm{a}, \mathrm{b})$ stated that the increase in intraocular pressure when in a recumbent position is in some way directly proportional to the initial intraocular pressure; this complicates our dependence on Goldmann tonometry as that procedure is performed routinely only in the sitting position.

The present study, as well as making a clinical evaluation of the Mackay-Marg tonometer and the pneumatonograph, assesses the relationship of various postures to intraocular pressure in normal and glaucomatous eyes. The study was conducted using two of the more modern rapid applanation tonometers: the pneumatonograph (PTG)* and the Mackay-Marg electric tonometert as both are easily portable and continuously monitor the pressure on graph paper, and in addition, they can be used in any posture with equal ease and precision. Neither do they require the magnification or illumination of a slit-lamp nor the use of fluorescein, as is essential in Goldmann tonometry. The pneumatonograph (Jain and Marmion, 1976) and the Mackay-Marg (Kaufman, Wind, and Waltman, 1970) can be used to record exact pressures in cases of ectatic corneas or postkeratoplasty (Irvine and Kaufman, 1969) as it is not imperative to apply the tip of the probe to the centre of the cornea in either procedure.

The correlation of the PTG (Jain and Marmion, *Alcon Applanation Pneumatonograph TM, Alcon Universal Ltd,
Fortworth, USA

†Berkely Model 255 Mackay-Marg Electronic Tonometer with Model Probe 200

Address for reprints: V. J. Marmion, Consultant Ophthalmic Surgeon, Bristol Eye Hospital, Bristol
1976) and the Mackay-Marg (Tierney and Rubin, I966) with the Goldmann has been shown to be significant, although the mean pressures recorded by the PTG and the Mackay-Marg are reported to be about $\mathrm{I}$ and $2 \mathrm{~mm}$ higher than those using the Goldmann.

The main difference between the two instruments is that the pneumatonograph is a combination of a pneumatic and an electronic system, whereas the Mackay-Marg is purely electronic and, when applanated, its recording system is driven by the slightest movement of the fuzed quartz plunger rod. The pneumatonograph has the advantage that the applanation is confirmed by a continuous whistle and the pressure can be read instantaneously from the digital display as well as from recordings on the chart. Applanation is simpler with the Mackay-Marg but its accuracy cannot be confirmed and hence it is essential to make 4 to 5 applanations each time to obtain a correct recording. The Mackay-Marg tonometer requires calibration daily before use, whereas the PTG need be calibrated only once a week. The Mackay-Marg is quicker in the sense that single applanation requires only about a second whereas the PTG requires 2 to 5 seconds.

Precise study of amplitude of ocular pulse with the PTG is a distinct advantage in the diagnosis of carotid occlusion, since the amplitude of ocular pulse is significantly affected even in cases with 20 per cent carotid obstruction (Best and Rogers, 1974).

\section{Material and methods}

The cases studied comprised three groups. Group I consisted of 20 normal young volunteers (40 eyes) with an age range of between 15 and 29 years. The postural study in this group was conducted only by the pneumatonograph.

Group 2 consisted of patients without glaucoma, routinely attending the outpatient clinic and who corresponded in age with the glaucomatous subjects. Patients included in this group were completely normal, cataractous, aphakics, or had defective vision or, in some cases, had some retinal disease such as diabetic retinitis, retinitis pigmentosa, etc. 
Group 3 were all patients with open-angle glaucoma and were selected as follows:

Those with previously undiagnosed glaucoma with intraocular pressures exceeding $22 \mathrm{mmHg}$.

Those receiving treatment but with intraocular pressures exceeding $20 \mathrm{mmHg}$.

Group 3 also included adequately controlled glaucomatous patients who were advised to stop treatment for at least 24 hours before the study was conducted. Patients in this group were selected according to their initial sitting pressure readings using the pneumatonograph. The number of patients included in Group 2 was 76 ( 15 I eyes) and in Group 354 (108 eyes) with an age range of between 30 and 85 years.

The pneumatonograph and the Mackay-Marg instruments were connected to the mains, adjusted, and calibrated as required. The Mackay-Marg tonometer used in this study required calibration to 9.5 . The PTG sensor tip has to be sterilized in 70 per cent isopropyl alcohol and a new autoclaved thin rubber tonocover was used for each new patient for the Mackay-Marg probe. The sequence of examination in this study was as follows.

The patient was comfortably seated erect on an examination couch and the eyes were anaesthetized with drops of 0.4 per cent benoxinate hydrochloride. The patient was asked to fix some object and avoid squeezing while he held his gaze. The tip of the Mackay-Marg probe was applanated to the apical zone of the cornea for about half a second. Four to five applanations were repeated in each eye. While applanating, care was taken that the centre of the probe was the first thing to make contact with the cornea and the withdrawal was abrupt. Soon after, with the patient in the same position, the tip of the PTG sensor probe was applanated to the apical zone of the cornea for about two to five seconds. A correct applanation was confirmed by a continuous whistle from the machine and the intraocular pressure was displayed as well as being recorded on the chart.

Thereafter, the patient was asked to lie face upwards on the same couch and, after two minutes, the pressure was recorded by both the Mackay-Marg and the PTG. The patient continued to lie in the same position and the pressure was re-recorded after three minutes using the same instruments. Then a pillow with an effective thickness of $12.7 \mathrm{~cm}$ was placed underneath the patient's head and pressure was recorded after two minutes. Having done that, the patient was made to sit erect as originally and the pressure was recorded at two- and fiveminute intervals. This way, with both tonometers, six separate pressure readings were obtained in various postures for each patient in Groups 2 and 3 .

To make the study more valid the following precautions were taken:

I. All measurements were performed by the same examiner.

2. The Mackay-Marg tonometer was calibrated daily and the PTG once in seven days.

3. All examinations were conducted on the same examination couch and hence the patient was not required to walk even a single step.

4. Patients were requested to keep their eyes gently closed during intervals to avoid any evaporation from anaesthetized cornea.

\section{Results}

AGE AND SEX DISTRIBUTION (Fig. I)

In Group I, the average age was 20.75 years and all the volunteers were women. In Groups 2 and 3, the ages ranged between 30 and 85 years with an average of $61 \cdot 72$ years, but in most cases $(80.77$ per cent) the ages ranged between 50 and 79 years with women predominating in almost all age groups giving an overall ratio of $13: 9$.

\section{PNEUMATONOGRAPH READINGS COMPARED WITH MACKAY-MARG}

Fig. 2 is the complete scattergram for Groups 2 and 3 (259 eyes). The Mackay-Marg readings are plotted on the ordinate and the pneumatonograph on the abscissa. The correlation coefficient (R) is

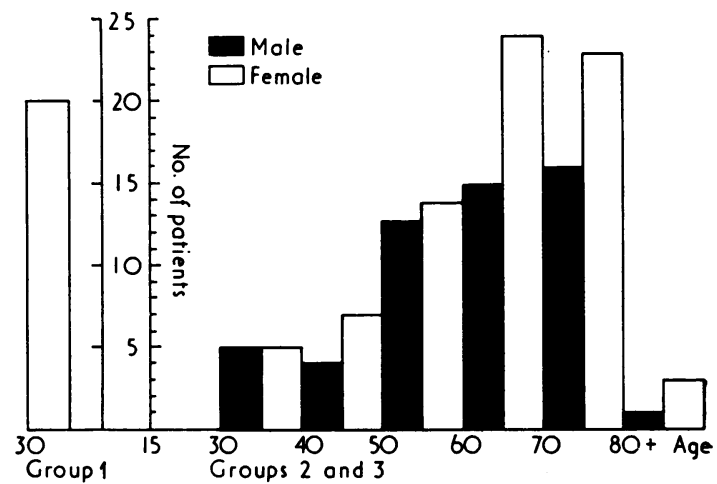

FIG. I Ages and sexes in Groups I, 2, and 3 (150 cases)

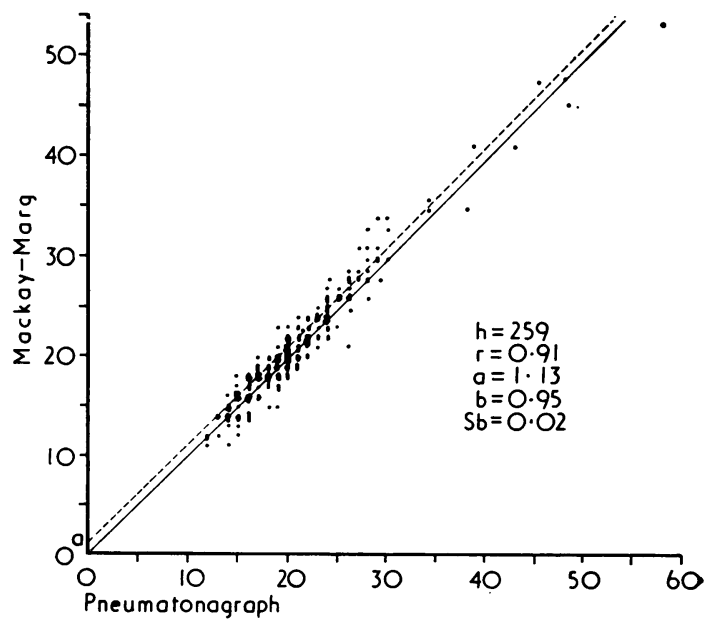

FIG. 2 Scattergram showing pneumatonograph and Mackay-Marg intraocular pressure readings for 259 eyes (Groups 2 and 3 ) in initial sitting posture 


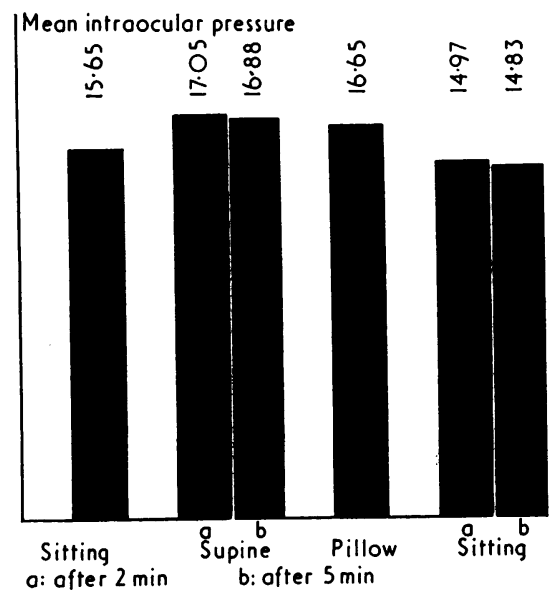

FIG. 3 Mean postural pressures in Group I volunteers (40 eyes) as recorded by pneumatonograph

0.91 . The calculated slope of the line is $0.95(b)$ and the standard error of the slope is 0.02. The intercept $(a)$ is $1_{1} \cdot \mathrm{I}_{3}$ and is interpreted to mean that the average Mackay-Marg reading is about I $\mathrm{mmHg}$ higher than the pneumatonograph reading.

POSTURAL CHANGE IN PRESSURE

Group I (Fig. 3). The mean initial intraocular pressure as recorded by the PTG was $15 \cdot 65 \pm 0.25$
$\mathrm{mmHg}$. There was an average increase in pressure of $\mathrm{I} \cdot 4 \mathrm{mmHg}$ within two minutes after lying supine (supine-a), then a slight decrease in supine (b) and 'pillow' positions, but the decrease was significant when the patient was again sitting. The mean intraocular pressure recorded in the end (sitting-b) was $0.82 \mathrm{mmHg}$ lower compared with the initial sitting intraocular pressure.

Groups 2 and 3. The results of the mean, standard error of the mean, and standard deviations of intraocular pressure recordings in various positions using the PTG and the Mackay-Marg tonometer for Groups 2 and 3, combined and separately, are shown in Fig. 4. The mean pressure recordings by Mackay-Marg were uniformly higher by approximately $\mathrm{I} \mathrm{mmHg}$ in all positions. Fig. 4 and Table I also show that there was a statistically significant increase in intraocular pressure when the patient changed from sitting to lying. The range of rise in pressure in non-glaucomatous subjects was -2 to $-8 \mathrm{mmHg}$ and in glaucomatous eyes it ranged between $\circ$ and $10 \mathrm{mmHg}$. The mean rise in pressure using the PTG was $2 \cdot 71,4.04$, and $3.28 \mathrm{mmHg}$ in Groups 2, 3, and 2 plus 3, respectively. Using the Mackay-Marg it was 2.5I, 3.72, and $2.79 \mathrm{mmHg}$ in the same order. After this initial rise, there was a slight fall in pressure in the supine posture and a greater fall when the pillow was placed under the head, but the fall was significant (mean fall ranging between $\mathrm{I} \cdot \mathrm{I} 5$ and $\mathrm{I} \cdot 95 \mathrm{mmHg}$ ) compared with the

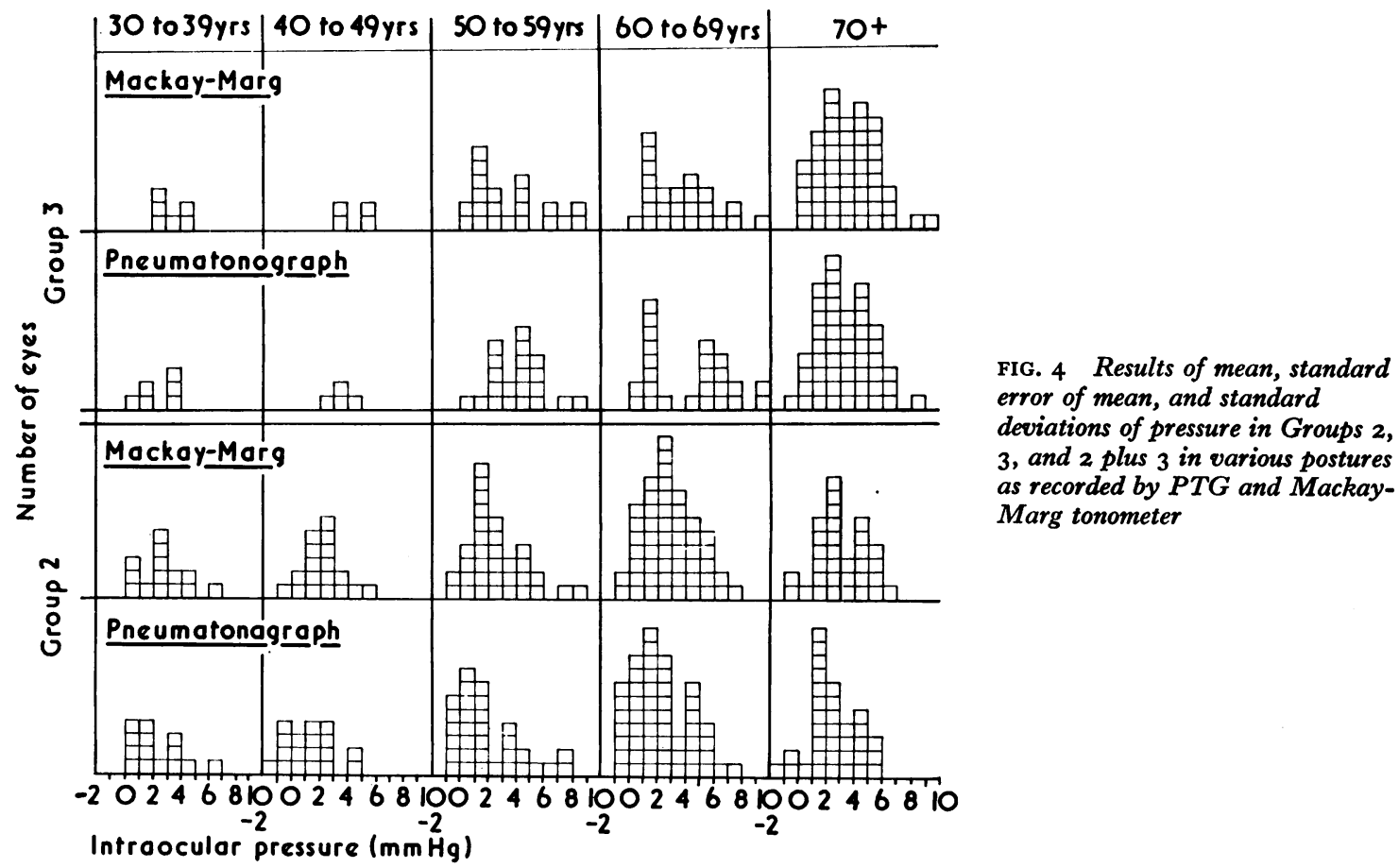


Table I Mean and range of variation in intraocular pressure in different postures in group 2 and group 3 separately and combined as recorded by pneumatonograph and Mackay-Marg tonometer

\begin{tabular}{|c|c|c|c|c|c|c|c|c|c|c|c|}
\hline \multirow{2}{*}{ Groups } & & \multicolumn{5}{|c|}{ Pneumatonograph } & \multicolumn{5}{|c|}{ Mackay-Marg tonometer } \\
\hline & & $\mathbf{I}$ & 2 & 3 & 4 & 5 & $\mathbf{I}$ & 2 & 3 & 4 & 5 \\
\hline $\begin{array}{l}2 \\
(151 \text { eyes })\end{array}$ & $\begin{array}{l}\text { Mean }(\mathrm{mmHg}) \\
\text { Range }(\mathrm{mmHg})\end{array}$ & $\begin{array}{c}2 \cdot 71 \\
-2 \text { to } 8\end{array}$ & $\begin{array}{c}0.26 \\
-2 \text { to } 3\end{array}$ & $\begin{array}{c}0.44 \\
-1 \text { to } 3\end{array}$ & $\begin{array}{c}0.30 \\
-2 \text { to } 3\end{array}$ & $\begin{array}{l}\text { I } 15 \\
0 \text { to } 3\end{array}$ & $\begin{array}{c}2 \cdot 5 I \\
-I \text { to } 8\end{array}$ & $\begin{array}{c}0.30 \\
-2 \text { to } 4\end{array}$ & $\begin{array}{c}0.32 \\
-1 \text { to } 4\end{array}$ & $\begin{array}{c}0.4 \mathrm{I} \\
-3 \text { to } 3\end{array}$ & $\begin{array}{l}\text { I'33 } \\
\text { o to } 4\end{array}$ \\
\hline $\begin{array}{l}3 \\
\text { (108 eyes) }\end{array}$ & $\begin{array}{l}\text { Mean }(\mathrm{mmHg}) \\
\text { Range }(\mathrm{mmHg})\end{array}$ & $\begin{array}{l}4.04 \\
0 \text { to } 10\end{array}$ & $\begin{array}{c}0.74 \\
-3 \text { to } 4\end{array}$ & $\begin{array}{c}0.64 \\
-2 \text { to } 3\end{array}$ & $\begin{array}{c}0.85 \\
-2 \text { to } 4\end{array}$ & $\begin{array}{l}1 \cdot 56 \\
\circ \text { to } 5\end{array}$ & $\begin{array}{l}3 \cdot 72 \\
0 \text { to } 10\end{array}$ & $\begin{array}{l}0.96 \\
-2 \text { to } 4\end{array}$ & $\begin{array}{c}0.86 \\
-2 \text { to } 4\end{array}$ & $\begin{array}{c}0.93 \\
-3 \text { to } 5\end{array}$ & $\begin{array}{l}1 \cdot 95 \\
0 \text { to } 5\end{array}$ \\
\hline $\begin{array}{l}2 \text { and } 3 \\
(259 \text { eyes) }\end{array}$ & $\begin{array}{l}\text { Mean }(\mathrm{mmHg}) \\
\text { Range }(\mathrm{mmHg})\end{array}$ & $\begin{array}{l}3 \cdot 28 \\
-2 \text { to } 10\end{array}$ & $\begin{array}{c}0.46 \\
-3 \text { to } 4\end{array}$ & $\begin{array}{c}0.52 \\
-2 \text { to } 3\end{array}$ & $\begin{array}{c}0.57 \\
-2 \text { to } 4\end{array}$ & $\begin{array}{l}1 \cdot 32 \\
\circ \text { to } 5\end{array}$ & $\begin{array}{l}2 \cdot 79 \\
-1 \text { to } 10\end{array}$ & $\begin{array}{l}0.55 \\
-2 \text { to } 4\end{array}$ & $\begin{array}{c}0.57 \\
-2 \text { to } 4\end{array}$ & $\begin{array}{l}0.54 \\
-3 \text { to } 5\end{array}$ & $\begin{array}{l}I \cdot 8 \mathrm{I} \\
0 \text { to } 5\end{array}$ \\
\hline
\end{tabular}

I = Supine ( $2 \mathrm{~min}$ ) minus sitting (initial); $2=$ Supine $(2 \mathrm{~min})$ minus supine $(5 \mathrm{~min}) ; 3=$ Supine $(5 \mathrm{~min})$ minus pillow under head; $4=$ Sitting ( $2 \mathrm{~min}$ ) minus sitting $(5 \mathrm{~min}) ; 5=$ Sitting (initial) minus sitting $(5 \mathrm{~min})$

initial pressure when the patient was again sitting (Table I). The variation in pressure was greater in glaucomatous than in non-glaucomatous subjects. The classical clinical PTG pressure recordings in various postures in two typical cases is shown in Figs 5 and 6.

The results shown in Table II explore the possibility of any relationship in age with the postural rise in pressure. There were few patients in the age groups 30 to 39 and $80+$ and if they are excluded there would appear to be a direct relationship between postural rise in pressure and age in the age group 50 to 79 years in Group 2, as shown by recordings of both the PTG and the Mackay-Marg (Table II). Fig. 7, which shows the frequency distribution of postural pressure rise in Groups 2 and 3 at various ages confirms this observation. Comparative postural rise to a higher degree is evident in older age groups, particularly in glaucomatous patients; 16.67 per cent in Group 2 and 5.34 per cent eyes in Group 3 showed no change in pressure as recorded by the PTG, and I4 per cent of Group 2 even showed a fall in pressure of $\mathrm{I}$ to $2 \mathrm{mmHg}$ by PTG. In none of the

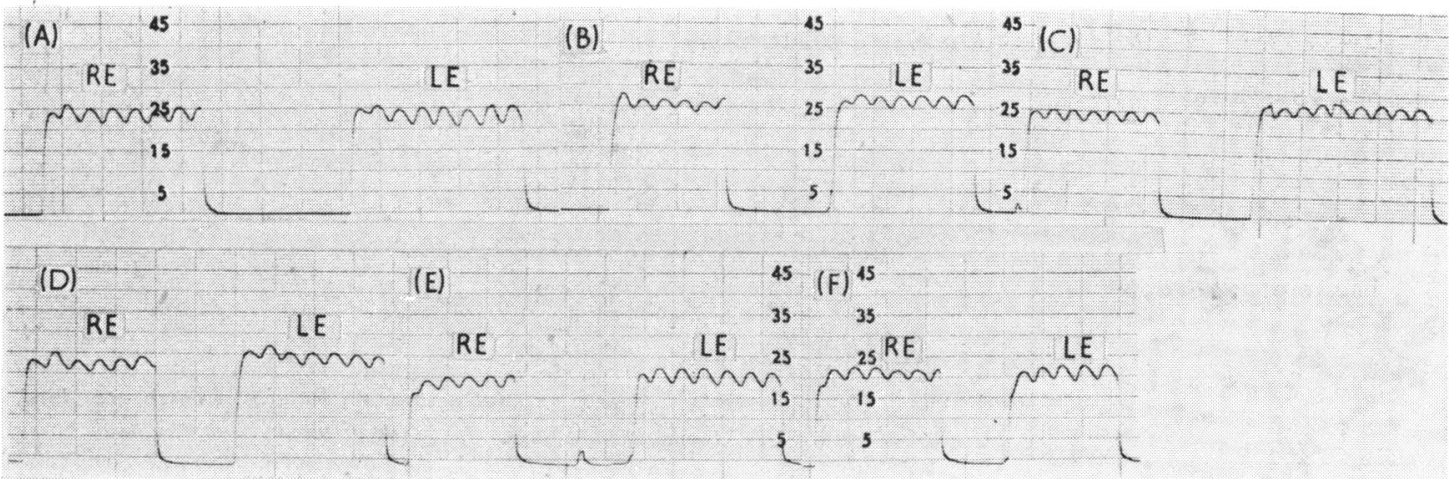

FIG. 5 Shows clinical PTG pressure recordings of both eyes in various postures-(a) sitting, (b) supine 2 min, (c) supine 5 min, (d) pillow under head, (e) sitting 2 min, (f) sitting 5 min

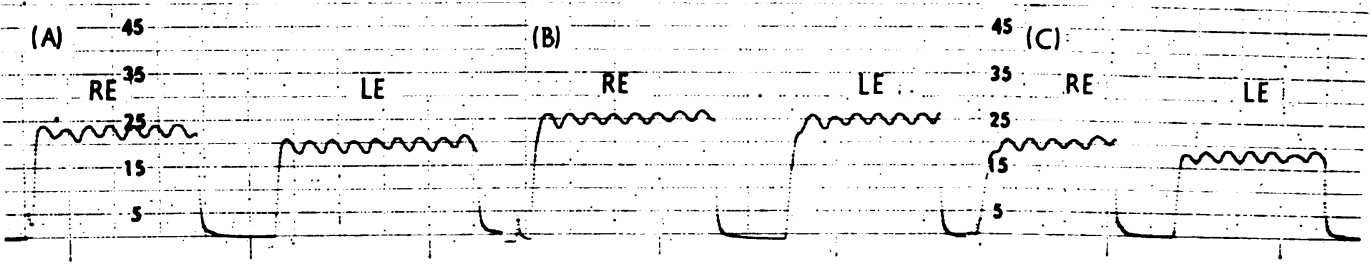

FIG. 6 Clinical PTG pressure recordings in three postures-(a) sitting, (b) supine, (c) sitting 
Table II Mean rise in intraocular pressure in various age groups from sitting to supine (2 minutes) posture in group 2 and 3 as recorded by PTG and Mackay-Marg tonometer

\begin{tabular}{|c|c|c|c|c|c|c|c|}
\hline \multirow{3}{*}{ Age groups } & \multirow{3}{*}{ No. of eyes } & \multirow{3}{*}{ Group 2} & \multirow{3}{*}{ Group 3} & \multicolumn{4}{|c|}{ Mean postural change (sitting to supine-2 min) } \\
\hline & & & & \multicolumn{2}{|c|}{ Pneumatonograph } & \multicolumn{2}{|c|}{ Mackay-Marg } \\
\hline & & & & Group 2 & Group 3 & Group 2 & Group 3 \\
\hline 30 to 39 & 20 & 14 & 6 & $2 \cdot 78$ & $\mathbf{2} \cdot \mathbf{8 3}$ & $2 \cdot 54$ & $2 \cdot 92$ \\
\hline 40 to 49 & 22 & 18 & 4 & $1 \cdot 87$ & 4.00 & $2 \cdot 00$ & 3.75 \\
\hline 50 to 59 & 54 & 33 & 21 & $2 \cdot 73$ & $4 \cdot 20$ & $2 \cdot 32$ & $4 \cdot 24$ \\
\hline 60 to 69 & 77 & 52 & 25 & $2 \cdot 79$ & $4 \cdot 80$ & $2 \cdot 45$ & $4 \cdot 67$ \\
\hline 70 to 79 & 78 & 32 & 46 & 3.09 & $4 \cdot 10$ & $2 \cdot 85$ & $4 \cdot 24$ \\
\hline $80+$ & 8 & 2 & 6 & 3.00 & $3 \cdot 17$ & $2 \cdot 95$ & $3 \cdot 21$ \\
\hline \multirow[t]{2}{*}{ Total } & 259 & 151 & 108 & $16 \cdot 26$ & $24 \cdot 54$ & $15 \cdot 31$ & $23 \cdot 03$ \\
\hline & & & Mean & $2 \cdot 71$ & $4: 04$ & $2 \cdot 51$ & $3 \cdot 72$ \\
\hline
\end{tabular}

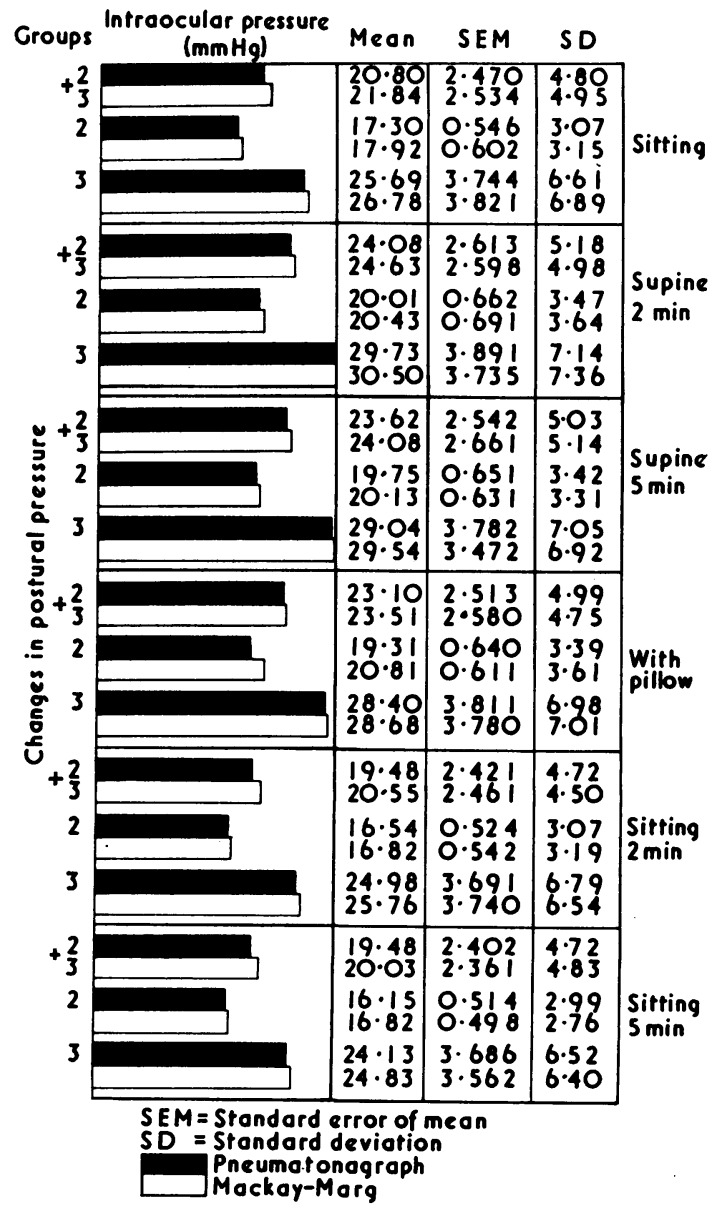

FIG. 7 Frequency distribution histogram of change in pressure from sitting to supine (two minutes) in relation to age groups in Groups 2 and 3 by PTG and

Mackay-Marg tonometer glaucomatous patients was there any fall in pressure when in the supine position.

On the whole, the increase most frequently observed in Group 2 was of 1 to $2 \mathrm{mmHg}$ in 40 per cent by the PTG and in 46 per cent by the Mackay-Marg, whereas in Group 3 it was 2 to $3 \mathrm{mmHg}$. In Group 2, an increase in pressure of $5 \mathrm{mmHg}$ or more was observed in 12.67 per cent using the PTG and 9.34 per cent using the MackayMarg, whereas in Group 3 it was 25 and 27.78 per cent, suggesting higher frequency of high postural change in glaucomatous patients compared with non-glaucomatous subjects.

\section{Discussion}

The first indentation tonometer was introduced by the Utrecht School, but the most reliable instrument during the first half of the twentieth century was undoubtedly the Schiötz (1909). Weighted applanation tonometry was first conceived by Maklakoff in 1885 and a resurgence of interest in applanation tonometry in the more scientific form (Goldmann, 1957) greatly improved the accuracy of this form of measurement. Both indentation and Maklakoff applanation tonometry are carried out when the patient is lying down. Goldmann applanation tonometry, on the other hand, is carried out when the patient is erect. For this, among other reasons, it is difficult to compare the two methods. An investigation of this difference has led to the discovery that postural pressure changes occur, but that both the Mackay-Marg tonometer and the pneumatonograph operate independently of posture.

Tierney and Rubin (1966) showed that the Mackay-Marg tonometer corresponds with the Goldmann applanation method to within $2 \mathrm{mmHg}$. The work of Quigley and Langham (1975) and Jain and Marmion (1976) has shown that the PTG and 
Table III Comparative figures of postural increase in intraocular pressure as observed by various workers

\begin{tabular}{|c|c|c|c|c|c|}
\hline \multirow{8}{*}{$\begin{array}{l}\text { Armaly and Salamoun (r963) } \\
\text { Galin and others (1963) } \\
\text { Robert and Rogers (1964) } \\
\text { Hetland-Eriksen (1966a) } \\
\text { Tarkkanen and Leikola (1967) } \\
\text { Krieglestein and Langham (1975) }\end{array}$} & \multirow{3}{*}{$\begin{array}{l}\begin{array}{l}\text { No. of } \\
\text { eyes }\end{array} \\
\frac{76}{6}\end{array}$} & \multirow{3}{*}{$\begin{array}{l}\text { Mean IOP } \\
\text { while sitting } \\
\text { (mmHg) } \\
14.73\end{array}$} & \multirow{3}{*}{$\begin{array}{l}\text { Mean increase } \\
\text { in pressure } \\
\text { (mmHg) } \\
2 \cdot 63\end{array}$} & \multicolumn{2}{|l|}{ Instrument used } \\
\hline & & & & \multirow{2}{*}{$\frac{\text { Sitting }}{\text { Goldmann }}$} & \multirow{2}{*}{$\frac{\text { Recumbent }}{\text { Goldmann (lying on side) }}$} \\
\hline & & & & & \\
\hline & 40 & 15.63 & $3 \cdot 04$ & Goldmann & Goldmann (lying on side) \\
\hline & I 5 I & $18 \cdot 80$ & $2 \cdot 20$ & Goldmann & Goldmann (supine) \\
\hline & 76 & $32 \cdot 57$ & $4 \cdot 74$ & Goldmann & Goldmann (lying on side) \\
\hline & 74 & $15 \cdot 0$ & $I \cdot 40$ & Mackay-Marg & Mackay-Marg (supine) \\
\hline & 90 & 14.0 & $2 \cdot 50$ & PTG & PTG (supine) \\
\hline & 32 & $17 \cdot 0$ & $4 \cdot 30$ & P'TG & PTG (supine) \\
\hline & 20 & $28 \cdot 9$ & $5 \cdot 00$ & PTG & PTG (supine) \\
\hline \multicolumn{6}{|l|}{ Jain and Marmion ( 1976 ) } \\
\hline Group I & 40 & $15 \cdot 65$ & $I \cdot 40$ & PTG & P'TG (supine) \\
\hline \multirow[t]{2}{*}{ Group 2} & I 5 I & $17 \cdot 30$ & $2 \cdot 71$ & PTG & PTG (supine) \\
\hline & & $17 \cdot 92$ & $2 \cdot 51$ & Mackay-Marg & Mackay-Marg (supine) \\
\hline \multirow[t]{2}{*}{ Group 3} & 108 & $25 \cdot 69$ & $4 \cdot 04$ & PTG & PTG (supine) \\
\hline & & $26 \cdot 78$ & $3 \cdot 72$ & Mackay-Marg & Mackay-Marg (supine) \\
\hline \multirow[t]{2}{*}{ Groups 2 and 3} & 259 & $20 \cdot 80$ & $3 \cdot 28$ & PTG & PTG (supine) \\
\hline & & $21 \cdot 84$ & $2 \cdot 79$ & Mackay-Marg & Mackay-Marg (supine) \\
\hline
\end{tabular}

Goldmann readings correspond in normal eyes to within less than $\mathrm{I} \mathrm{mmHg}$. The current study on intraocular pressure on 259 eyes using the PTG and the Mackay-Marg indirectly confirmed these observations and showed that the mean reading using the Mackay-Marg was higher by $\mathrm{I}^{\mathrm{I}} \mathrm{I} 3 \mathrm{mmHg}$ than that of the PTG. Consistency of readings in each instrument served as a cross check on the postural change in intraocular pressure.

There is a significant increase in intraocular pressure when a normal subject changes from sitting to lying down. Although Fig. 4 and Table I indicate that there is some degree of a decrease in pressure within five minutes of assuming the recumbent posture, a sample of $I 5$ patients (30 eyes) after the initial five-minute period showed a degree of consistency in the recordings which suggests that any fall occurring after that time would be slight. A reduction in the degree of increase in intraocular pressure is mitigated by adoption of a semi-recumbent position (one pillow) which raises the head to about fifteen degrees, and a return to the original or less than the original pressure occurs on resuming the erect posture.

The rise in intraocular pressure is dependent partly on the initial intraocular pressure, but this increase is significantly higher in the 50 to 79 year age group. This takes into account the rectification required for disparity in numbers, the proportion of women to men, and the initial difference in intraocular pressures. The results for young people correlate well with those of Tarkkanen and Leikola (1967), although the average age was higher in their report and the mean intraocular pressure slightly lower (Table III). In the older age group comparable to the distribution in chronic simple glaucoma, the results obtained confirm those published by Armaly and Salamoun (1963), Galin and others (1963), and Robert and Rogers (1964). The mean postural pressure changes were higher than in the Group 2 reported here, particularly in the recumbent position, partly because the patients were examined lying on their sides. The results of Quigley and Langham (1975) are uniformly higher for which there is at present no explanation.

The principal postural changes in circulatory dynamics are related to changes in the blood volume which decreases in the erect posture after about 30 minutes as a result of hydrostatic capillary changes. There is a fall in blood pressure in recumbency associated with increased minute volume which occurs rapidly, usually within 30 seconds. The rapidity with which the intraocular pressure increases in the recumbent position would indicate that this is a reflex phenomenon governed by a baroreceptor type mechanism, and the fine adjustment that can occur in time and on adjustment of posture supports this hypothesis. Hydrostatic changes as mediated through venous pressure, capillary perfusion, and blood volume movements, would take longer to produce an effect by change in posture. Age would also tend to accentuate this change and if the baroreceptor mechanism were the basis for it, it would be expected that this would increase with age.

The mean postural change in glaucomatous patients is significantly higher than in the nonglaucomatous group. This is basically in agreement with the work of Hetland-Eriksen (1966a) and Krieglestein and Langham (1975), but it was neither universal nor uniform (Fig. 7); 8 per cent of glaucomatous eyes had no change in intraocular 
pressure, 24 per cent had an increase which was within the bounds noted on a normal gaussian curve, and an increase in intraocular pressure of more than $5 \mathrm{mmHg}$ was observed approximately three times more frequently in glaucomatous than in non-glaucomatous eyes. The maximum rise recorded by us was $10 \mathrm{mmHg}$ in glaucomatous eyes and $8 \mathrm{mmHg}$ in non-glaucomatous eyes. The glaucomatous eyes take longer to adjust after the rise, as shown by the divergence of results in the semi-recumbent to erect posture. This reflects the inability of the glaucomatous eye to compensate for change in pressure and offers a simple testing method for potential glaucomatous change in aqueous humour dynamics. If the postural changes in pressures are going to be used as a diagnostic procedure in glaucoma, it is important to take into account that aspect of the orientation of the pressure, particularly if the postural rise has not been very remarkable.

Four further clinical aspects of the postural rise merit consideration. First, the role posture can play in the production of change at the optic disc in cases of glaucoma and so-called low-tension glaucoma where the increased intraocular pressure when lying down is associated with a fall in blood pressure, although this may be partly mitigated by a slightly increased blood volume. Secondly, medical treatment cannot be regarded as being successful unless the highest intraocular pressure can be contained within normal limits for a particular eye. This is so for stressful conditions, diurnal rises, and also postural changes in pressure. Thirdly, the effect of surgery on the postural rise is important because of the initial reverse effect during the actual operative procedure and, also in the event of surgery proving better in controlling the glaucomatous rise in recumbency, it would be an indication for opting for this course of treatment. Finally, the postural pressure rise should be of consideration in all intraocular operations and may possibly account for some of the vitreous problems such as vitreous upthrust in cataract surgery.

The mechanism of the glaucomatous postural change should be examined further in conjunction with phasic variation, plasma cortisone fluctuation, and other hydrostatic mechanisms. Such investigations could possibly give some indication to the basic mechanism of the response and the variation that occurs.

\section{Summary}

A postural study was conducted in three separate groups of subjects. The first group comprised 20 women volunteers with an average age of 20.75 years. In this group, the study was conducted by the pneumatonograph only. Mean pressure recorded was $15.65 \pm 0.25 \mathrm{mmHg}$ and there was an average rise of $1.4 \mathrm{mmHg}$ in supine posture.

Groups 2 and 3 comprised I 5 I non-glaucomatous and 108 glaucomatous eyes respectively in the age range of 30 to 85 years. In these two groups, the study was conducted using the PTG and the Mackay-Marg tonometer. Clinical evaluation of the Mackay-Marg with the PTG gave significant correlation, with mean Mackay-Marg readings being $I \cdot 13 \mathrm{mmHg}$ higher.

The intraocular pressure when changing from seated to the supine position increased on average by 2.71 and $4.04 \mathrm{mmHg}$, respectively in Groups 2 and 3 and by 2.51 and $3.72 \mathrm{mmHg}$ by Mackay-Marg, suggesting a higher change in glaucomatous subjects. Pressure on resumption of sitting was found to be lower than the initial pressure. Postural change also showed some direct relationship with age in non-glaucomatous subjects.

\section{References}

ANDERSON, D. R., and GRANT, W. M. (1973) Invest. Ophthal., 12, 204 armaly, M. F., and Salamoun, s. G. (1963) Arch. Ophthal., 70, 603 BEST, M., and ROGRRS, R. (1974) Ibid., 92, 54

GALIN, M. A., MCIVOR, J. W., and MAGRUDER, G. B. (1963) Amer. F. Ophthal., 55, 720

GoldmanN, H. (1957) In 'Glaucoma' (Transactions of the Second Conference 1956). Macy Foundation, New York HETLAND-ERIKSEN, J. (1966a) Acta ophthal. (Kbh.), 44, 5 I 5

$$
\text { (1966) Ibid., 44, } 522
$$

INGLimA, R. (1966) Eye, Ear, Nose Thr. Monthly, 45, 64

IRVINE, A. R., and KAUFMAN, H. E. (1969) Amer. F. Ophthal., 68, 835

JAIN, M. R., and MARMION, v. J. (1976) Brit. $\mathcal{~ . ~ O p h t h a l . , ~ 6 0 , ~ I 0 7 ~}$

kaufman, H. E., Wind, C. A., and waltman, s. R. (1970) Amer. F. Ophthal., 69, 1003

KRIEGLESTEIN, G. K., and LANGHAM, M. E. (1975) Ophthalmologica (Basel), I7I, I32

LANGHAM, M. E., and MCCARTHY, E. (1968) Arch. Ophthal., 79, 389

MAKLAKOFF (1885) Arch. Ophtal. (Paris), 4, 159

QUigley, H. A., and LANGham, M. E. (1975) Amer. Y. Ophthal., 80, 266

ROBERTS, W., and ROGERS, J. W. (1964) Ibid., 57, I I I

SCHIÖTZ, H. (1909) Arch. Augenheilk,. 62, 317

TARKKANEN, A., and LeIKOLA, J. (1967) Acta ophthal. (Kbh.), 45, 569

TIERNEY, J. P., and RUBIN, M. L. (1966) Amer. F. Ophthal., 62, 263 